G. P., twenty-one years of age, actor, had always been healthy up to his ninth year, when, running he fell and struck his head against the corner of a wall, receiving a deep wound of the left fronto-parietal region. Soon after, especially when angry, he noticed a difficulty in pronouncing certain words; especially was this noticeable in words beginning with $b$ or $l$. This soon became so prominent that he was forced to substitute for these, words commencing with other letters. $\mathrm{He}$ obtained some improvement from electric treatment. His general health was excellent. In the left fronto-parietal region, near the outer extremity of the fronto-parietal suture, a semi-lunar cicatrix, $5 \mathrm{~cm}$. long, was discovered, together with some depression of the skull and slight irregularity of surface. In speaking the patient often repeated the first syllables of some words, interrupted and hesitated, not knowing how to express the word representing his idea. He said that in his mind he could form the word exactly, but in order to pronounce it he must mentally repeat it several times. With the assistance of a suggester he speaks fluently. Variations of atmosphere had an influerce upon his affection. He desired, at any cost, to be freed from his defect, which in his case-an actor's-was of serious importance. The cranial lesion itself being situated almost exactly over Broca's centre, trepanation was thought justifiable. A trephine with a diameter of two and a half centimetres was applied. The bony disc was found to be of irregular thickness, the dura was slightly adherent to the smooth inner table, which on being detached gave rise to some venous hæmorrhage. The disc was not replaced, as it did not exactly fit the opening after it was trimmed. The wound healed by first intention, and on the seventh day the patient left his bed. Already fourteen days after the operation the patient could speak with greater facility and regularity, which was quite evident to any one hearing him.

F. H. P.

\title{
A RARE NEUROSIS OF THE TONGUE AND BUCCAL CAVITY.
}

Bernhardt describes four cases, one male and three females, in which the patients complained of a prickling and burning of the mouth, and especially the tongue, which came on paroxysmally and would sometimes disturb sleep or prevent speech. It varied in intensity. These sensa- 
tions in most cases were situated on the left margin of the tongue; but in two cases they extended to the mucous membrane of the mouth, upon the floor of the buccal cavity, the cheeks, gums and jaws. Nothing could be perceived in the fauces; only in one case did the membrane of the tongue present the appearance of folds and crevices. All the patients were over thirty years of age, and in good health. Examination revealed nothing abnormal. Two of the female patients wore false teeth, which must be taken into consideration. The fourth patient, a lady, had an excellent set of natural teeth. These abnormal sensaiions torment the patients exceedingly, and, above all, the fear of a "cancer" forced them all to seek medical aid, caused them several times a day carefully to examine their tongues in the mirror, and, in short, embittered their existence. These patients would be quiet for hours together, and did not impress as being hypochondriacs. This neurosis is by no means unknown in the French literature. Already in 1887 Fournier and Labbré, at a lecture given by Verneuil upon imaginary ulcers of the tongue, remarked that there were such patients, and that neuropathic individuals suffer from such a neurosis as frequently at least as rheumatic or gouty persons. The nervous disease of speech may be of grave importance, a premonitory symptom of tabes dorsalis or dementia paralytica which will follow. The writer, on the contrary, shows that the disease may exist alone and persist for years. Grave physiological disturbances, as of taste, movement or general sensation, were not present in his cases. Treatment in general is powerless. He used the bromides, cocaine locally, nitrate of silver, the thermo-cautery, iron, arsenic, but with only temporary benefit. More relief was obtained from electric treatment of the tongue and palate with the induced and constant current. (Gazzetta Medica di Roma, No. I 5, r89r.) 